\title{
Clarification on the applicability of systematic reviews
}

Haddaway, N.R.; Bayliss, H.R.

\section{Frontiers in Ecology and the Environment}

\author{
DOI: \\ 10.1890/15.WB.003 \\ Published: 01/04/2015 \\ Publisher's PDF, also known as Version of record \\ Cyswllt i'r cyhoeddiad / Link to publication
}

Dyfyniad o'r fersiwn a gyhoeddwyd / Citation for published version (APA):

Haddaway, N. R., \& Bayliss, H. R. (2015). Clarification on the applicability of systematic reviews. Frontiers in Ecology and the Environment, 13(3), 129. https://doi.org/10.1890/15.WB.003

\footnotetext{
Hawliau Cyffredinol / General rights

Copyright and moral rights for the publications made accessible in the public portal are retained by the authors and/or other copyright owners and it is a condition of accessing publications that users recognise and abide by the legal requirements associated with these rights.

- Users may download and print one copy of any publication from the public portal for the purpose of private study or research.

- You may not further distribute the material or use it for any profit-making activity or commercial gain

- You may freely distribute the URL identifying the publication in the public portal ?

Take down policy

Copyright by the Ecological Society of America

Take down policy

If you believe that this document breaches copyright please contact us providing details, and we will remove access to the work immediately and investigate your claim.
} 
=

Clarification on the applicability of systematic reviews

In their recent article, Dafforn et al. (Front Ecol Environ 2015; 13[2]: 82-90) reviewed the literature on marine urbanization to produce a conceptual framework for the design of multifunctional marine artificial structures. Their review highlighted the rapid increase in marine urbanization and the well-documented ecological impacts of marine infrastructure. The authors stated that "a systematic review was not possible given that much of the relevant literature crosses scholarly disciplines and is located in books, conference proceedings, and gray literature that would not have appeared in searches". While we fully agree that such a topic poses challenges in terms of searching across subject domains and incorporating the substantial utility of gray literature, we felt compelled to draw attention to common misconceptions regarding systematic reviews.

Systematic reviews were developed within the medical discipline around 25 years ago and have since been adapted for use in a variety of subjects, including environmental management and conservation (Pullin and Stewart 2006). Systematic reviews aim to provide reliable summaries of evidence in a transparent, objective, and repeatable manner: something that would undoubtedly benefit the topic discussed in Dafforn et al.'s review. The systematic review approach improves on the traditional review process in various ways. First, an a priori plan for the systematic review is established in a protocol document, which is peer-reviewed and published for each review. The review then proceeds according to this plan: searching for literature from a wide array of sources using a predetermined search strategy that has been tested by the reviewers to ensure that it returns known relevant research; screening all identified search records for rele- vance against a set of predefined inclusion criteria set out in the protocol, at title, abstract, and then fulltext levels; critically appraising identified studies for their robustness and potential for bias using a planned appraisal strategy; extracting metadata and study results; synthesizing the findings of all included studies in a quantitative way where possible; and drafting a highly detailed report of the review - including lists of excluded studies and reasons - which is then peer-reviewed and published (Pullin and Stewart 2006). Since its relatively recent introduction to the environmental sciences, the method has become accepted as an established form of publication (Lortie 2014) and is now widely viewed as a gold standard in evidence synthesis, attracting substantial interest and investment from major international funders, such as the Science and Technical Advisory Panel of the United Nations (eg Pullin et al. 2013). More than 60 systematic reviews have been published in the environmental sciences (www.environmentalevidence.org), and some 6000 systematic reviews covering medical topics have been published in the Cochrane Library (www.thecochranelibrary.com).

Dafforn et al. stated that a systematic review was not possible due to the multidisciplinary nature and the high volume of gray literature of their research topic. Multidisciplinary systematic reviews may face additional challenges, including searching databases from different disciplines to ensure adequate topic coverage, but such reviews are increasingly common: for instance, between environmental management and development (eg Waddington et al. 2014) and biodiversity protection and human well-being (eg Pullin et al. 2013). A further major strength of systematic reviews relative to traditional reviews is that the former make considerable efforts to identify relevant studies from the gray literature in an attempt to counter publication bias and ensure that other forms of evidence, such as industry reports, are detected.

In summary, Dafforn et al. may have had many reasons not to undertake a systematic review, a task that is often considered as resource-intensive and time-consuming. However, the multidisciplinary nature of their chosen topic and the importance of including gray literature are good reasons to embrace the robustness and transparency of the systematic review, which not only is amenable to addressing this type of question but also offers several methodological advantages over traditional narrative reviews.

Neal R Haddaway ${ }^{1 *}$ and

Helen R Bayliss ${ }^{2}$

${ }^{1}$ MISTRA EviEM, Royal Swedish

Academy of Sciences, Stockholm,

Sweden

*(neal_haddaway@hotmail.com);

${ }^{2}$ Centre for Evidence-Based

Conservation, Bangor University,

Bangor, UK

Lortie CJ. 2014. Formalized synthesis opportunities for ecology: systematic reviews and meta-analyses. Oikos 123: 897-902.

Pullin AS and Stewart GB. 2006. Guidelines for systematic review in conservation and environmental management. Conserv Biol 20: 1647-56.

Pullin AS, Bangpan M, Dalrymple S, et al. 2013. Human well-being impacts of terrestrial protected areas. Environ Evid 2: 19 .

Waddington $\mathrm{H}$, Snilstveit B, Hombrados JG, et al. 2014. Farmer field schools for improving farming practices and farmer outcomes in low-and middleincome countries: a systematic review. Campbell Syst Rev 2014: 6.

doi: $10.1890 / 15$.WB.003

D

\section{The authors' reply}

In "Marine urbanization: an ecological framework for designing multifunctional artificial structures", we reviewed selected literature on ecological engineering in terrestrial and marine environments. We then introduced a conceptual framework for designing artificial structures to reduce negative ecological impacts while supporting desired ecosystem services. We appreciate Haddaway and Bayliss' comments and agree 
with the argued benefits and importance of systematic reviews, and their potential to improve research in marine urbanization and other disciplines. Indeed we have been authors on many recent systematic reviews and meta-analyses (Airoldi 2003; Johnston and Roberts 2009; McKinley and Johnston 2010; Roberts et al. 2010; Hedge et al. 2013; Ferrario et al. 2014; Strain et al. 2014; Johnston et al. 2015). In our paper in Frontiers, rather than declaring that a systematic review was not possible, we should have said that a systematic review was not the ideal approach; just because something is possible does not mean that it is the best strategy. We take this opportunity to also caution against following a monolithic approach to scientific review and discussion. To promote a more rigorous and inclusive debate we instead encourage a diversity of strategies that would enable various opinions to be voiced and that would better suit the purpose of the review. In our case, we decided against conducting a systematic review because we deliberately wanted to highlight the variety of approaches used up to this point and to draw inspiration from practices applied in terrestrial "green" engineering, which are rarely explored in marine systems. Furthermore we expanded upon specific case studies (many of which were not subject to peer review) that had either positive or negative outcomes and that illustrated how marine artificial structures might be better designed in the future to meet multi-purpose objectives. Such a comprehensive assessment benefited our new conceptual framework, which we hope will be used by a range of practitioners including academics, environmental managers, engineers, and business operators.

Katherine A Dafforn ${ }^{1 *}$, Tim M Glasby $^{2}$, Laura Airoldi ${ }^{3,4}$, Natalie $\mathrm{K}$ Rivero ${ }^{1}$, Mariana Mayer Pinto ${ }^{1}$, and Emma L Johnston ${ }^{1}$ ${ }^{1}$ Evolution and Ecology Research Centre, School of Biological, Earth and Environmental Sciences, University of
New South Wales, Sydney, Australia *(k.dafforn@unsw.edu.au); ${ }^{2}$ Port

Stephens Fisheries Centre, New South

Wales, Department of Primary

Industries, Port Stephens, Australia;

${ }^{3}$ Dipartimento di Scienze Biologiche,

Geologiche e Ambientali, University of

Bologna, Bologna, Italy; ${ }^{4}$ Hopkins

Marine Station, Stanford University,

Pacific Grove, CA

Airoldi L. 2003. The effects of sedimentation on rocky coast assemblages. Oceanogr Mar Biol 41: 161-236.

Ferrario F, Beck MW, Storlazzi CD, et al. 2014. The effectiveness of coral reefs for coastal hazard risk reduction and adaptation. Nat Commun 5: art3794.

Hedge LH, Johnston EL, Ayoung ST, et al. 2013. Sydney Harbour: a systematic review of the science. Sydney, Australia: Sydney Institute of Marine Science.

Johnston EL and Roberts DA. 2009. Contaminants reduce the richness and evenness of marine communities: a review and meta-analysis. Environ Pollut 157: 1745-52.

Johnston EL, Mayer-Pinto M, and Crowe TP. 2015. Chemical contaminant effects on marine ecosystem functioning. J Appl Ecol 52: 140-49.

McKinley A and Johnston EL. 2010. Impacts of contaminant sources on marine fish abundance and species richness: a review and meta-analysis of evidence from the field. Mar Ecol-Prog Ser 420: 175-91.

Roberts DA, Johnston EL, and Knott NA. 2010. Impacts of desalination plant discharges on the marine environment: a critical review of published studies. Water Res 44: 5117-28.

Strain E, Thomson RJ, Micheli F, et al. 2014. Identifying the interacting roles of stressors in driving the global loss of canopy-forming to mat-forming algae in marine ecosystems. Global Change Biol 20: 3300-12.

doi:10.1890/15.WB.004

\section{The role of impact characterization in carbon footprinting}

The ever-accelerating growth in atmospheric carbon emissions constitutes the greatest anthropogenic disturbance to the Earth's climate system. As a result, mitigating global warming through reduction of carbon emissions receives top priority among climateengineering strategies (Cusack et al. 2014). In the pursuit of transitioning to lower carbon output, the concept of the "carbon footprint" (CF) was born, with the intent to raise consumer and stakeholder awareness by attributing the responsibility for carbon emissions to products, individuals, organizations, industries, or nations. Although $\mathrm{CF}$ is internationally recognized as a measure of anthropogenic climate impacts, particularly in the field of life-cycle assessment (LCA) (Hellweg and Milà i Canals 2014), ambiguity, confusion, and controversy surrounding its meaning still exist.

Of particular concern is what CF actually measures and how it deviates from the "ecological footprint" (EF) (Borucke et al. 2013). CF follows the logic of the LCA framework, in which activities are first translated into the inventory of emissions (resource extractions can be treated on the same level of life-cycle inventory) and further processed in a subsequent characterization step, in which the inventory results (emissions or extractions) are modeled quantitatively and expressed as impact scores according to their relative contributions to a specific impact category. By contrast, EF translates a given activity into emissions and extractions that are then aggregated into land area required for absorption and regeneration, by a simple conversion that does not involve any characterization modeling. Having recognized probably the most important difference between CF and EF, Hammond (2007) unexpectedly argued that the term "footprint" implies a form of area-based indicator, and that CF should thus be renamed "carbon weight" due to its mass unit. This may appear to be an argument over semantics, but underneath is a deeper issue that may indicate a misinterpretation of the term "footprint" and of the rationale behind the CF calculation. We discuss these issues below.

Simply put, footprints are measures of anthropogenic impacts on the planet's environment irrespective of their precise units and dimensions. CF assesses not only carbon emissions but also non-carbon green- 